\title{
Editorial: Stressors Acting on Aquatic Ecosystems: High-Throughput Sequencing Approaches to Shed Light on Human-Nature Interactions
}

\author{
Antonia Bruno $^{1 *}$, Maurizio Casiraghi ${ }^{1}$, Melina Bautista $^{2}$ and Mehrdad Hajibabaei ${ }^{3}$ \\ ${ }^{1}$ ZooPlantLab, Biotechnology and Biosciences Department, University of Milano-Bicocca, Milan, Italy, ${ }^{2}$ Carollo Engineers, \\ Sarasota, FL, United States, ${ }^{3}$ Department of Integrative Biology, Centre for Biodiversity Genomics, University of Guelph, \\ Guelph, ON, Canada
}

Keywords: aquatic ecosystem, environmental DNA (eDNA), high-throughput sequencing, stressors, biodiversity

\author{
Editorial on the Research Topic
}

Stressors Acting on Aquatic Ecosystems: High-Throughput Sequencing Approaches to Shed Light on Human-Nature Interactions

Aquatic ecosystems are unique sources of biodiversity. However, anthropogenic pressures are threatening ecosystem equilibrium, with an unprecedented loss of biodiversity. This has tremendous intrinsic, societal, and economic impacts, considering the ecosystem services supported by micro- and macro-biodiversity (IPBES, 2019; Ruckelshaus et al., 2020).

\section{OPEN ACCESS}

Edited and reviewed by:

Annie Machordom

National Museum of Natural Sciences (MNCN), Spain

*Correspondence: Antonia Bruno

antonia.bruno@unimib.it

Specialty section:

This article was submitted to Evolutionary and Population Genetics, a section of the journal

Frontiers in Ecology and Evolution

Received: 23 August 2021 Accepted: 04 October 2021

Published: 28 October 2021

Citation:

Bruno A, Casiraghi M, Bautista $M$ and Hajibabaei M (2021) Editorial:

Stressors Acting on Aquatic Ecosystems: High-Throughput Sequencing Approaches to Shed Light on Human-Nature Interactions.

Front. Ecol. Evol. 9:763442. doi: 10.3389/fevo.2021.763442
Traditional methods, based mainly on morphological traits to describe the biodiversity, have provided the basis for classification of species, but they cannot estimate the total biodiversity at a global scale and much remains to be discovered (Li et al., 2010).

Nowadays, the adoption of DNA-based analyses to facilitate rapid, large-scale biomonitoring efforts represents the natural progression for biodiversity assessments to shed light on humannature interactions (Porter and Hajibabaei, 2018; Makiola et al., 2020).

In particular, methods that employ environmental DNA (eDNA) are invaluable, together with proper experimental design and analyses, to describe and study changes in biodiversity in a non-invasive and effective way (DiBattista et al., 2020; Makiola et al., 2020). We can say that eDNA coupled with high-throughput DNA sequencing techniques (i.e., DNA metabarcoding) revolutionized the way in which we can assess ecosystem health and preserve Earth's biodiversity (Hajibabaei, 2012; Casiraghi et al., 2016; Deiner et al., 2017).

Compson et al. reviewed 1,563 articles published about DNA metabarcoding and summarized how this approach is rapidly changing the attitude toward a global bioassessment effort. Among the great advantages of applying DNA-based techniques to revolutionize biomonitoring, there is the ability to assess biota at a holistic ecosystem level: across the whole Tree of Life (Hajibabaei et al., 2016; Stat et al., 2017), from microbes to mammals.

Starting from the microscopic world, Bruno et al. used DNA metabarcoding to explore the microbial community and its dynamics in a drinking water treatment plant (DWTP). DWTPs are engineered ecosystems that harbor a peculiar microbial community (Bruno et al., 2018; Oh et al., 2018). Potabilization processes can be considered chronic stressors having effects on the intrinsic biodiversity of source water (Bautista-de los Santos et al., 2016; Castelle and Banfield, 2018; Dai et al., 2020). Indeed, source water harbors an astonishing biodiversity of uncultivable environmental bacteria, and it is stable over time, seeding water downstream. However, the microbial community structure detected from water flushing from the filters used to remove 
chemical contaminants (granular activated carbon filters) is changing over time, depending on the colonization dynamics of the filter substrate. Looking at a deeper level, also filter raw material affected microbiome assembly with significant variation in the relative abundances of specific taxa. This evidence suggested that filters are a fully-fledged ecological niche, thus providing the chance to purposely engineered filter microbial communities, to produce biologically stable drinking water.

This collection of papers also allowed a thoughtful accounting of the role of the "unseen" faunal diversity inhabiting extreme environments such as hydrothermal vents deep-sea hard substrata.

Cowart et al. integrated morphological identification methods with eDNA metabarcoding to investigate the recolonization dynamics of benthic faunal communities living on the Montségur edifice within the Lucky Strike vent field (Mid-Atlantic Ridge), after an induced disturbance that consisted of faunal clearance within experimental quadrats. This study sheds light on the recovering potential of such extreme ecosystems, exploiting the advantages and overcoming the limitations of different methods often presented in opposition to each other: morphological identification and DNA metabarcoding.

On a broader perspective, such multi-level integration allows informed conservation and management decisions in relation to the protection of aquatic ecosystems.

For an effective management of fisheries, together with preserving biodiversity, the study of Pavičić et al. supported the routine adoption of molecular techniques. They focused their attention on the European lobster (Homarus gammarus), an intensively fished crustacean species in the Adriatic Sea which reaches high market value. Highly selective fishing has the potential to permanently change the characteristics within a population and could drive the decline of genetic diversity. Molecular techniques, such as microsatellites analysis and partial COI region sequencing, revealed that the decrease in population size due to overfishing, habitat degradation, and other anthropogenic stressors did not significantly affect neutral genetic diversity. Also, populations in the northeastern Adriatic act as a genetic source for surrounding areas, clearly suggesting that the protection of these populations will be beneficial for both fisheries and conservation management.

Thus, these studies clearly demonstrate the importance of understanding the potential impact of human intervention on the ecology of aquatic ecosystems.

Going forward, studying stressors acting on aquatic ecosystems includes a detailed monitoring of species dispersal to evaluate the success of restoration actions. Rhine sculpin (Cottus rhenanus) is a fish species that has been reintroduced into a recently restored stream within the Emscher catchment in Germany. Thanks to an eDNA-based approach, Hempel et al. tracked the dispersal of Rhine sculpin at a fine spatial and temporal scale. The sensitivity of an eDNA-based method showed a higher dispersal potential of the species than what was assumed. Moreover, the results, validated also by traditional electrofishing methods, demonstrated the successful re-establishment of the target species in restored streams. This indicates that a good ecological status has been achieved, supporting the restoration action undertaken and the use of eDNA-based approach for the monitoring of aquatic ecosystems recovery.

In addition to novel discoveries, the ideas and perspectives suggested can potentially be used to revolutionize research in the future. The studies collected here paint a compelling picture of the complex interactions among all the players shaping the equilibrium of aquatic ecosystems, spanning from the unseen majority of environmental microorganisms to the bioindicators species belonging to the eukaryotic domain. Humans must be considered actors as well. Noteworthy, Compson et al. outlined the different stakeholders, ranging from academic to industry and governments, who can benefit from the widespread adoption of DNA metabarcoding, supported by the number of studies exponentially increasing.

However, eDNA-based methods are still evolving and their pros and cons should be considered for each application (Lacoursière-Roussel and Deiner, 2021). Hence, effective use of these methods require a deep understanding of the process to derive a correct biological interpretation of the huge amount of data obtained (Goldberg et al., 2016; Zinger et al., 2019). To compound the issue further, yet to date, there is no consensus on the most appropriate theoretical framework, methods, and measures to study exogenous stressors and associated ecosystem impacts. Nevertheless, such awareness, together with a robust experimental design, should drive the formulations of the hypothesis to be tested and will pave the way for new questions to be addressed.

A major challenge facing resource managers is a lack of scalable tools to measure Earth's biodiversity rapidly and consistently, as highlighted by Compson et al. A comprehensive and multidimensional framework to study ecosystems under stress by integrating data that spans the entire spectrum of biodiversity and elucidating connections between natural and engineered systems is the key factor. Foremost, synergy among different sectors is a fundamental prerequisite, but also it will serve as a boost for the adoption of the next generation bioassessment. Finally, environmental stewardship can benefit from community-based biomonitoring, overcoming the challenges of data collection and boosting the involvement of non-expert in biodiversity issues (Robinson et al., 2021).

\section{AUTHOR CONTRIBUTIONS}

All authors listed have made a substantial, direct and intellectual contribution to the work, and approved it for publication.

\section{ACKNOWLEDGMENTS}

We would like to thank the entire editorial board at Frontiers in Ecology and Evolution, in particular P. Hohl, R. Fernandes and E. Bodenham, for their constant and effective support in developing this Research Topic. 


\section{REFERENCES}

Bautista-de los Santos, Q. M., Schroeder, J. L., Sevillano-Rivera, M. C., Sungthong, R., Ijaz, U. Z., Sloan, W. T., et al. (2016). Emerging investigators series: microbial communities in full-scale drinking water distribution systems-a meta-analysis. Environ. Sci. Wat. Res. 2, 631-644. doi: 10.1039/C6EW00030D

Bruno, A., Sandionigi, A., Bernasconi, M., Panio, A., Labra, M., and Casiraghi, M. (2018). Changes in the drinking water microbiome: effects of water treatments along the flow of two drinking water treatment plants in a urbanized area, Milan (Italy). Front. Microbiol. 9:2557. doi: 10.3389/fmicb.2018.02557

Casiraghi, M., Galimberti, A., Sandionigi, A., Bruno, A., and Labra, M. (2016). Life with or without names. Evol. Biol. 43, 582-595. doi: 10.1007/s11692-016-9384-5

Castelle, C. J., and Banfield, J. F. (2018). Major new microbial groups expand diversity and alter our understanding of the tree of life. Cell 172, 1181-1197. doi: 10.1016/j.cell.2018.02.016

Dai, Z., Sevillano-Rivera, M. C., Calus, S. T., Bautista-de los Santos, Q. M., Eren, A. M., Van Der Wielen, P. W., et al. (2020). Disinfection exhibits systematic impacts on the drinking water microbiome. Microbiome 8:42. doi: 10.1186/s40168-020-00813-0

Deiner, K., Bik, H. M., Mächler, E., Seymour, M., Lacoursière-Roussel, A., Altermatt, F., et al. (2017). Environmental DNA metabarcoding: transforming how we survey animal and plant communities. Mol. Ecol. 26, 5872-5895. doi: $10.1111 / \mathrm{mec} .14350$

DiBattista, J. D., Reimer, J. D., Stat, M., Masucci, G. D., Biondi, P., De Brauwer, M., et al. (2020). Environmental DNA can act as a biodiversity barometer of anthropogenic pressures in coastal ecosystems. Sci. Rep. 10:8365. doi: 10.1038/s41598-020-64858-9

Goldberg, C. S., Turner, C. R., Deiner, K., Klymus, K. E., Thomsen, P. F., Murphy, M. A., et al. (2016). Critical considerations for the application of environmental DNA methods to detect aquatic species. Methods Ecol. Evol. 7, 1299-1307. doi: 10.1111/2041-210X.12595

Hajibabaei, M. (2012). The golden age of DNA metasystematics. Trends Genet. 28, 535-537. doi: 10.1016/j.tig.2012.08.001

Hajibabaei, M., Baird, D. J., Fahner, N. A., Beiko, R., and Golding, G. B. (2016). A new way to contemplate Darwin's tangled bank: how DNA barcodes are reconnecting biodiversity science and biomonitoring. Philos. T. R. Soc. B 371:20150330. doi: 10.1098/rstb.2015.0330

IPBES (2019). Global Assessment Report on Biodiversity and Ecosystem Services of the Intergovernmental Science-Policy Platform on Biodiversity and Ecosystem Services. Bonn: IPBES Secretariat.

Lacoursière-Roussel, A., and Deiner, K. (2021). Environmental DNA is not the tool by itself. J. Fish Biol. 98, 383-386. doi: 10.1111/jfb.14177

Li, L., Zheng, B., and Liu, L. (2010). Biomonitoring and bioindicators used for river ecosystems: definitions, approaches and trends. Proc. Environ. Sci. 2, 1510-1524. doi: 10.1016/j.proenv.2010.10.164
Makiola, A., Compson, Z. G., Baird, D. J., Barnes, M. A., Boerlijst, S. P., Bouchez, A., et al. (2020). Key questions for next-generation biomonitoring. Front. Environ. Sci. 7:197. doi: 10.3389/fenvs.2019.0 0197

Oh, S., Hammes, F., and Liu, W. T. (2018). Metagenomic characterization of biofilter microbial communities in a full-scale drinking water treatment plant. Wat. Res. 128, 278-285. doi: 10.1016/j.watres.2017.1 0.054

Porter, T. M., and Hajibabaei, M. (2018). Scaling up: a guide to highthroughput genomic approaches for biodiversity analysis. Mol. Ecol. 27, 313-338. doi: 10.1111/mec.14478

Robinson, C. V., Baird, D. J., Wright, M. T. G., Porter, T. M., Hartwig, K., Hendriks, E., et al. (2021). Combining DNA and people power for healthy rivers: implementing the STREAM community-based approach for global freshwater monitoring. Perspect. Ecol. Conserv. 19, 279-285. doi: 10.1016/j.pecon.2021.03.001

Ruckelshaus, M. H., Jackson, S. T., Mooney, H. A., Jacobs, K. L., Kassam, K. A. S., Arroyo, M. T., et al. (2020). The IPBES global assessment: pathways to action. Trends Ecol. Evol. 35, 407-414. doi: 10.1016/j.tree.2020.01.009

Stat, M., Huggett, M. J., Bernasconi, R., DiBattista, J. D., Berry, T. E., Newman, S. J., et al. (2017). Ecosystem biomonitoring with eDNA: metabarcoding across the tree of life in a tropical marine environment. Sci. Rep. 7:12240. doi: 10.1038/s41598-017-12501-5

Zinger, L., Bonin, A., Alsos, I. G., Bálint, M., Bik, H., Boyer, F., et al. (2019). DNA metabarcoding-need for robust experimental designs to draw sound ecological conclusions. Mol. Ecol. 28, 1857-1862. doi: 10.1111/mec.15060

Conflict of Interest: The authors declare that the research was conducted in the absence of any commercial or financial relationships that could be construed as a potential conflict of interest.

Publisher's Note: All claims expressed in this article are solely those of the authors and do not necessarily represent those of their affiliated organizations, or those of the publisher, the editors and the reviewers. Any product that may be evaluated in this article, or claim that may be made by its manufacturer, is not guaranteed or endorsed by the publisher.

Copyright $\odot 2021$ Bruno, Casiraghi, Bautista and Hajibabaei. This is an open-access article distributed under the terms of the Creative Commons Attribution License (CC $B Y)$. The use, distribution or reproduction in other forums is permitted, provided the original author(s) and the copyright owner(s) are credited and that the original publication in this journal is cited, in accordance with accepted academic practice. No use, distribution or reproduction is permitted which does not comply with these terms. 